\title{
Dating the Siple Dome (Antarctica) ice core by manual and computer interpretation of annual layering
}

\author{
Kendrick C. TAYlor, ${ }^{1}$ Richard B. Alley, ${ }^{2}$ Debra A. MeESE ${ }^{3}$ Matthew K. SPENCER, ${ }^{2}$ \\ Ed J. BROOK, ${ }^{4}$ Nelia W. DUNBAR,${ }^{5}$ Robert C. FINKEL, ${ }^{6}$ Anthony J. GOW, ${ }^{3}$ \\ Andrei V. KURbatov, ${ }^{7}$ Gregg W. LAMOREY, ${ }^{1}$ Paul A. MAYEWSKi ${ }^{7}$ Eric A. MEYERson, ${ }^{7}$ \\ Kunihiko NISHIIZUMI, ${ }^{8}$ Gregory A. ZIELINSKI ${ }^{7}$ \\ ${ }^{1}$ Desert Research Institute, University and Community College System of Nevada, Reno, Nevada 89512, U.S.A. \\ E-mail:kendrick@dri.edu \\ ${ }^{2}$ Department of Geosciences and EMS Environment Institute, The Pennsylvania State University, University Park, Pennsylvania 16802-7501, \\ U.S.A. \\ ${ }^{3}$ U.S. Army Cold Regions Research and Engineering Laboratory, 72 Lyme Road, Hanover, New Hampshire 03755-1290, U.S.A. \\ ${ }^{4}$ Geology and Environmental Science, Washington State University, 14204 NE Salmon Creek Ave., Vancouver, Washington 98686, U.S.A. \\ ${ }^{5}$ New Mexico Bureau of Mines and Mineral Resources, Earth and Environmental Sciences Department, New Mexico Tech, 801 Leroy Place, \\ Socorro, New Mexico 87801, U.S.A. \\ ${ }^{6}$ Center for Accelerator Mass Spectrometry, Lawrence Livermore National Laboratory, Box 808, Livermore, California 94550, U.S.A. \\ ${ }^{7}$ Climate Change Institute, University of Maine, 303 Bryand Global Sciences Center, Orono, Maine 04469, U.S.A. \\ ${ }^{8}$ Space Sciences Laboratory, University of California, Berkeley, Berkeley, California 94720, U.S.A.
}

\begin{abstract}
The Holocene portion of the Siple Dome (Antarctica) ice core was dated by interpreting the electrical, visual and chemical properties of the core. The data were interpreted manually and with a computer algorithm. The algorithm interpretation was adjusted to be consistent with atmospheric methane stratigraphic ties to the GISP2 (Greenland Ice Sheet Project 2) ice core, ${ }^{10}$ Be stratigraphic ties to the dendrochronology ${ }^{14} \mathrm{C}$ record and the dated volcanic stratigraphy. The algorithm interpretation is more consistent and better quantified than the tedious and subjective manual interpretation.
\end{abstract}

\section{INTRODUCTION}

The deep Siple Dome ice core (SDM-A) was drilled in 1999 to investigate paleoclimate and glaciological topics. It is located on the Siple Coast, West Antarctica, between Kamb and Bindschadler Ice Streams (former Ice Streams C and D) $\left(81.65^{\circ} \mathrm{S}, 148.81^{\circ} \mathrm{W}\right.$; $621 \mathrm{~m}$ elevation $)$ and extends $1004 \mathrm{~m}$ to the bed. A variety of chemical, physical and isotopic measurements were made on the core. To interpret these measurements it is necessary to know the age of the ice as a function of depth. At Siple Dome, the current annual ice accumulation rate is $13.2 \mathrm{~cm} \mathrm{a}^{-1}$ (Hamilton, 2002). The annual layers can be identified by seasonal variations in the chemistry, electrical conductivity and visual appearance of the ice. The depth to which the annual layers can be recognized is limited by diffusion of ions and isotopes in the ice that averages out annual variations, and by ice flow that reduces the thickness of annual layers as depth increases.

Annual layers in ice cores are associated with approximately regularly spaced local maxima in a seasonal indicator, such as the acidity of the ice or hoar-frost layers. It would be easy to interpret the records if each year was exactly like the previous year and was associated with a layer thick enough that the seasonal indicator could be conveniently measured. The situation is complicated by other factors such as variations in the amplitude of the seasonal maximum, surficial post-depositional processes such as drifting and melting, and changes in annual ice accumulation. At some locations and depths, the seasonal signal dominates other influences, making it easy to interpret the records (e.g. the Summit Greenland ice cores have outstanding annual layers between 1600 and $2000 \mathrm{~m}$ ). At other locations, the seasonal signal is not recorded because surficial processes mix snow deposited over several years before it can metamorphose to ice (e.g. Taylor Dome, Vostok, Antarctica). Siple Dome is between these extremes, and interpretation of annual layers is possible but not trivial.

The datasets must be interpreted to identify annual layers, which are then counted to determine the age of the ice. The interpretation can be done manually, examining and interpreting the data associated with each annual layer, or by using a computer algorithm. We applied both methods to the Siple Dome ice core and developed a time-scale that extends to 8610 years $\mathrm{BP}$, where an age of $0 \mathrm{BP}$ is assigned to AD 1950.

\section{AVAILABLE DATASETS}

Electrical conductivity measurement uses a direct current to measure the electrical impedance of ice as a function of depth (Hammer, 1983; Taylor and others, 1992), and is controlled by the acidity of the ice. Seasonal variations in electrical conductivity occur because of seasonal variations in the acidity of the ice. The equipment used in this 


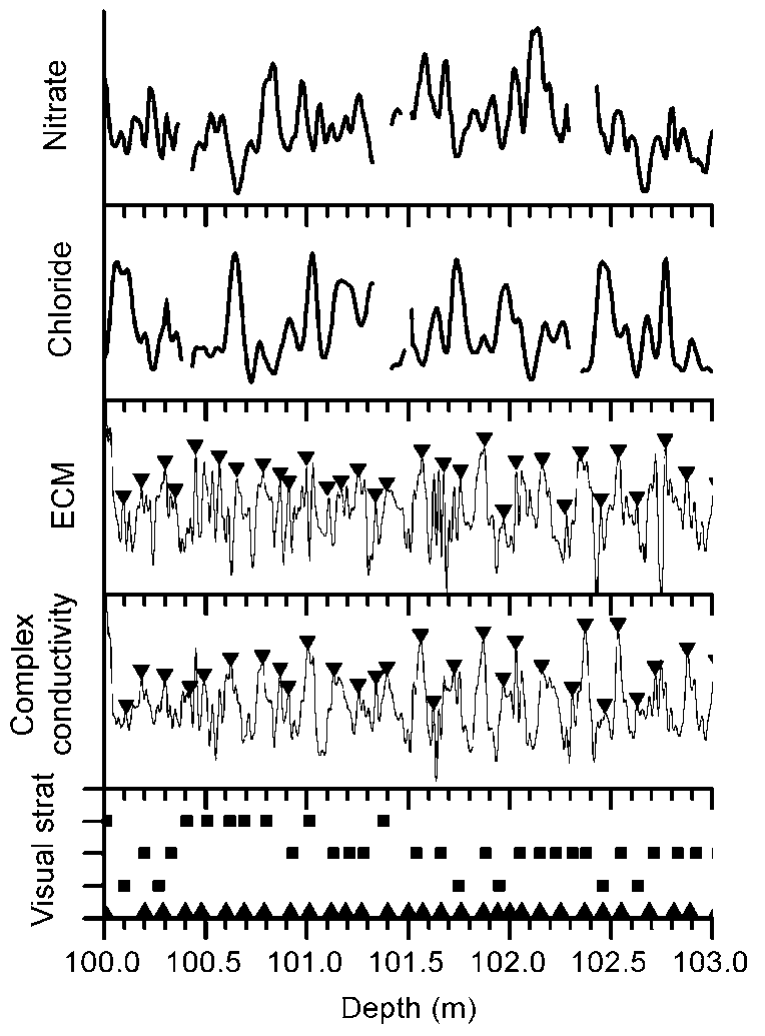

Fig. 1. Comparison of different records with seasonal variations. Measurements of the nitrate, chloride, electrical conductivity (ECM) and complex conductivity are shown from $100 \mathrm{~m}$ depth. Also shown on the electrical records are interpretations of annual layers by the computer algorithm discussed in this paper. The visual stratigraphy (bottom panel) was interpreted by two groups. One group (Pennsylvania State University; square symbol) ranked their confidence in the interpretation of each layer on a scale of one to three, with greater values indicating a greater level of confidence. The other group (Cold Regions Research and Engineering Laboratory; triangle symbol on bottom axis) did not record their confidence in their interpretation of each layer.

investigation measures the current flowing between two electrodes that are in contact with the ice and have a potential difference of $1000 \mathrm{~V}$. The electrodes are $1 \mathrm{~cm}$ apart, with a surface area of $4 \mathrm{~mm}^{2}$. The spatial resolution of the measurement is about $3 \mathrm{~mm}$.

The complex conductivity measurement uses an alternating current to measure the electrical impedance of the ice as a function of depth. There is a direct electrical connection between the electrodes and the ice. The equipment used in this investigation employs a frequency of $300 \mathrm{kHz}$, and measures the portion of the impedance that is out of phase with the applied voltage of $2 \mathrm{~V}$. The electrodes have a surface area of $16 \mathrm{~mm}^{2}$ and are $1 \mathrm{~cm}$ apart. A larger surface area is required for the complex conductivity measurement than for the electrical conductivity measurement to obtain a suitable electrical contact with the lower voltage of the alternating current source. The complex conductivity method is similar to the dielectric properties measurement (Moore and others, 1992), and both measurements respond to the concentrations of a variety of chemical species in the ice including chloride and acids. The spatial resolution of the complex conductivity measurement is about $6 \mathrm{~mm}$.

The visual appearance of the core was observed on a prepared surface of approximately $1 \mathrm{~m}$ long sections of core.
Table 1. Methane age-depth control points

\begin{tabular}{ccc}
\hline Depth at Siple Dome & $\begin{array}{c}\text { Age of corresponding } \\
\text { features in GISP2 }\end{array}$ & Age uncertainty \\
& & \\
$\mathrm{m}$ & kyr BP & $\mathrm{kyr}$ \\
\hline 514.78 & 8.61 & 0.55 \\
621.73 & 11.91 & 0.54 \\
646.71 & 13.20 & 0.65 \\
674.88 & 15.46 & 0.73 \\
680.38 & 15.73 & 0.68 \\
708.08 & 18.30 & 1.00 \\
729.15 & 23.81 & 1.13 \\
739.72 & 24.78 & 1.09
\end{tabular}

\footnotetext{
${ }^{1}$ The GISP2 age is the years before AD 1950 and considers the gas-ageice-age difference in the GISP2 and Siple Dome cores, following the technique used by Blunier and Brook (2001).

${ }^{2}$ The uncertainty includes the uncertainty in the dating of the GISP2 core, matching of the Siple Dome and GISP2 methane records, and in the gas-age-ice-age differences.
}

Many different light sources including diffuse-side, diffuseunderneath and fiber-optic-point sources were adjusted to produce the best conditions for viewing the core in a darkened room. At least two observers examined every $1 \mathrm{~m}$ long section of core for variations in transparency and scattering associated with annual layering. Visible annual layers are typically formed by warm summer air temperatures and near-surface solar heating that cause the formation of coarse-grained, low-density hoar layers, that contrast with winter higher-density, finer-grained deposits (Alley and others, 1997b). The grain-size difference is typically preserved during metamorphism (e.g. Alley and Woods, 1996), producing ice in which summer layers have fewer, larger bubbles per unit volume than nearby winter layers. Differences in the appearance of the ice caused by variations in density and the size of grains and bubbles were manually noted in logbooks.

The concentrations of the major ions $\left(\mathrm{Na}^{+}, \mathrm{Mg}^{2+}, \mathrm{K}^{+}\right.$, $\left.\mathrm{Ca}^{2+}, \mathrm{NH}_{4}{ }^{+}, \mathrm{Cl}^{-}, \mathrm{NO}_{3}{ }^{-}, \mathrm{SO}_{4}{ }^{2-}\right)$ and methanesulfonic acid were measured by ion chromatography in the uppermost $24 \mathrm{~m}$ of the core with a sample interval of $2 \mathrm{~cm}$, corresponding to eight to ten samples per year. Continuous measurements of $\mathrm{Cl}^{-}, \mathrm{NO}_{3}{ }^{-}$and liquid conductivity were also made to identify annual layers (Kreutz and others, 1997) in the uppermost $154 \mathrm{~m}$.

The visual, electrical and chemical measurements all respond to seasonal variations (Fig. 1) in different ways. The differences occur because the different measurements respond to different aspects of seasonal changes, differences in spatial resolution, measurement instrumentation effects and, in the case of the visual observations, the skill of the observer. Some ice properties influence several measurements; for example the concentration of $\mathrm{NO}_{3}{ }^{-}$influences the continuous measurement of $\mathrm{NO}_{3}{ }^{-}$, direct current electrical conductivity and the complex conductivity. However, some ice properties influence a single measurement; for example seasonal variations in bubble size are only observed by visual stratigraphy. It is widely recognized that the best way to identify annual layers is to have measurements of many seasonally varying parameters. Some of the measurements should be on unrelated properties such as ionic species associated with regional atmospheric transport, and hoar-frost layers that are influenced by local 
conditions. There is also a benefit to having measurements that are influenced to varying degrees by the same property (e.g. the acidity of the ice influences both types of electrical measurements). In general, the greater the redundancy of the measurements the higher the confidence will be in the final result.

Variations in atmospheric methane are globally synchronous, so features in the methane record in the Siple Dome core must occur at the same time as they occur in other cores (Blunier and Brook, 2001). It was possible to establish age-depth control points by comparing features in the Siple Dome and GISP2 (Greenland Ice Sheet Project 2) atmospheric methane records. Table 1 shows the methane age-depth control points during the time period when annual layers are detectable. (All ages in this paper are calendar years before AD 1950). The GISP2 core was dated by Meese and others (1997), who manually interpreted the dust, visual and electrical records in terms of annual layers.

The ${ }^{10} \mathrm{Be}$ in an ice core is primarily produced by the interaction of cosmic rays and the upper atmosphere. The rate at which ${ }^{10} \mathrm{Be}$ is produced is modulated by variations in solar activity and the geomagnetic field. These processes also modulate the production of ${ }^{14} \mathrm{C}$, such that there are irregularly spaced features that are common in records of ${ }^{14} \mathrm{C}$ and ${ }^{10} \mathrm{Be}$ (Beer and others, 1988; Finkel and Nishiizumi, 1997). Features in the ${ }^{10} \mathrm{Be}$ record in the Siple Dome core must occur before the features occur in ${ }^{14} \mathrm{C}$ dendrochronology records, because of time lags in the carbon cycle (Siegenthaler and Beer, 1988). At GISP2 we observed this offset to be about 20 years, which is consistent with our understanding of the carbon cycle. It was possible to establish stratigraphic tie points between the Siple Dome ${ }^{10} \mathrm{Be}$ record (shifted by 20 years) and the ${ }^{14} \mathrm{C}$ dendrochronology record (Stuiver and others, 1998). Table 2 shows the ${ }^{10} \mathrm{Be}$ age- depth control points.

Volcanic eruptions widely distribute tephra (volcanic ash) and aerosols. Some of the tephra particles and aerosols
Table 2. ${ }^{10}$ Be age-depth control points

\begin{tabular}{ccc}
\hline Depth & \multicolumn{1}{c}{$\begin{array}{c}\text { Age } \\
\text { years BP }\end{array}$} & $\begin{array}{c}\text { Age uncertainty } \\
\text { years }\end{array}$ \\
& & \\
\hline 59.7 & 350 & 40 \\
106.6 & 800 & 40 \\
126.8 & 1000 & 40 \\
165.1 & 1440 & 40 \\
179.1 & 1600 & 40 \\
191.4 & 1750 & 40 \\
234.0 & 2300 & 50 \\
\hline
\end{tabular}

may fall onto the surface of an ice sheet and become incorporated into the ice sheet. If tephra in an ice layer has the same chemistry as tephra from a large eruption known to have occurred close to the estimated age of the ice layer, the ice layer can be assigned the absolute age of the eruption (De Angelis and others, 1984; Palais and others, 1992; Zielinski and others, 1997). A preliminary time-scale was used to assign ages to a record of sulfate concentration. The dated sulfate record was used to hypothesize which sections of the core would contain tephra from specific volcanic eruptions of known age. Many of these sections contained tephra, which was analyzed with a Cameca SX-100 electron microprobe to measure the concentration of the major oxides of F, Na, Mg, Al, Si, P, S, Cl, K, Ca, Ti, Mn and Fe. Concentrations in the ice-core tephra were compared to concentrations of these oxides in deposits formed by specific eruptions known to have occurred around the initially assigned age of the ice from which the tephra was extracted. Glass shards analyzed in the Siple Dome ice core were linked to distinct magmatic provinces in Antarctica and potentially to other volcanic regions of the Southern Hemisphere, based on geochemical composition and calculated

Table 3.Volcanic age-depth control points

\begin{tabular}{|c|c|c|c|c|c|}
\hline Depth & Age & $\begin{array}{l}\text { Dating method and } \\
\text { age uncertainty }\end{array}$ & Volcano name & Volcanic signal & Source \\
\hline $\mathrm{m}$ & years BP & & & & \\
\hline 8.23 & -15 & $\begin{array}{l}\text { Layer-counting SDM- } 94 \\
\text { core }\left(\text { Kreutz and others, 1998) }{ }^{1} \text {; }\right. \\
\text { age range: } \pm \text { lyear }\end{array}$ & Agung, Indonesia & Sulfate correlation & Devine and others (1984) \\
\hline 33.62 & 140 & $\begin{array}{l}\text { Layer-counting SDM- } 94 \\
\text { core (Kreutz and others, 1998) }{ }^{1} \text {; } \\
\text { age range: } \pm 3 \text { years }\end{array}$ & $\begin{array}{l}\text { The Pleiades, Victoria } \\
\text { Land, Antarctica }\end{array}$ & $\begin{array}{l}\text { Sulfate and tephra } \\
\text { correlation }\end{array}$ & Dunbar and others (2003) \\
\hline 37.04 & 163 & $\begin{array}{l}\text { Layer-counting ITASE and } \\
\text { SDM- } 94 \text { cores }^{1} ; \\
\text { age range: } \pm 4 \text { years }\end{array}$ & $\begin{array}{l}\text { Melbourne, Melbourne } \\
\text { Province, Victoria Land, } \\
\text { Antarctica }\end{array}$ & $\begin{array}{l}\text { Sulfate and tephra } \\
\text { correlation }\end{array}$ & Dunbar and others (2003) \\
\hline 503.4 & 8200 & $\begin{array}{l}{ }^{39} \mathrm{Ar} /{ }^{40} \mathrm{Ar} \text { date; } \\
1 \sigma \text { range: } 5.6-10.7 \mathrm{kyr}\end{array}$ & Mount Takahe, West Antarctica & Tephra match & Wilch and others (1999) \\
\hline 549.5 & 10300 & $\begin{array}{l}{ }^{39} \mathrm{Ar} /{ }^{40} \mathrm{Ar} \text { date; } \\
1 \sigma \text { range: } 7.7-12.9 \mathrm{kyr}\end{array}$ & Mount Berlin, West Antarctica & Tephra match & Wilch and others (1999) \\
\hline 596.9 & 11100 & $\begin{array}{l}{ }^{14} \mathrm{C} \text { date; } \\
1 \sigma \text { range: } 12.91-10.96 \mathrm{kyr}\end{array}$ & Cerro Hudson, Chile & Tephra match & Haberle and Lumley (1998) \\
\hline 760.8 & 27300 & $\begin{array}{l}{ }^{39} \mathrm{Ar} /{ }^{40} \mathrm{Ar} \text { date; } \\
1 \sigma \text { range: } 25.0-29.6 \mathrm{kyr}\end{array}$ & Mount Berlin, West Antarctica & Tephra match & Dunbar and others (2003) \\
\hline
\end{tabular}

${ }^{1}$ These eruptions have been correlated using similarity in sulfate spike signatures in the Siple Dome A and SDM-94 (Kreutz and others, 1998) and ITASE ice cores. 


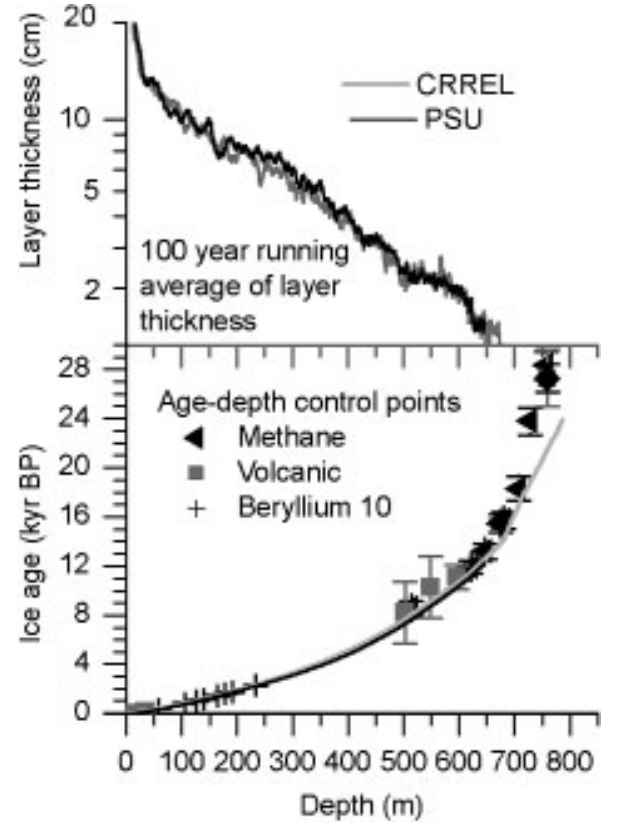

Fig. 2. Comparison of age control points and two manual interpretations of visual observations. CRREL, Cold Regions Research and Engineering Laboratory; PSU, Pennsylvania State University.

statistical similarities or differences between the two samples. We used a statistical distance $(D)$ function to establish the potential correlation of tephra particles to source volcanoes (Jeffries and others, 1995). If two analyses were perfectly identical, the $D$ value would be zero. However, because of statistical errors in the microprobe methodology used for shard analysis, the mean composition of two identical tephra samples should normally have a $D$ value of around four (Jeffries and others, 1995). Any value above ten suggests a low degree of similarity between samples. Five matches were found between the chemistry of tephra in the core and tephra from an eruption of known age (Table 3).

\section{INTERPRETATION METHODS}

\section{Manual interpretation of the visual stratigraphy}

The first approach to dating the core involved manual interpretation of the visual observations that were made over a 4 year period when the ice first became available. Two groups inspected most of the core independently. These groups occasionally discussed interpretation of the visible layers, but did not try for a single interpretation, choosing instead to use the degree of agreement as an indication of the reproducibility of the interpretations. Additional checks were also made, including having two stratigraphers from one group independently interpret selected core sections, and re-examination of selected core sections. Overall, these tests indicated the manual interpretation of the visual observations was reproducible to about $5 \%$ in Holocene ice. As the depth of the ice increases, ice flow results in thinner layers that make identification of annual layers more difficult, and eventually the less prominent annual layers are not detectable. One of the visual-stratigraphy groups chose to stop interpreting annual layers at about $650 \mathrm{~m} \mathrm{depth}$, because of large uncertainties in the interpretation and poor core quality. This group did notice possible annual layers in

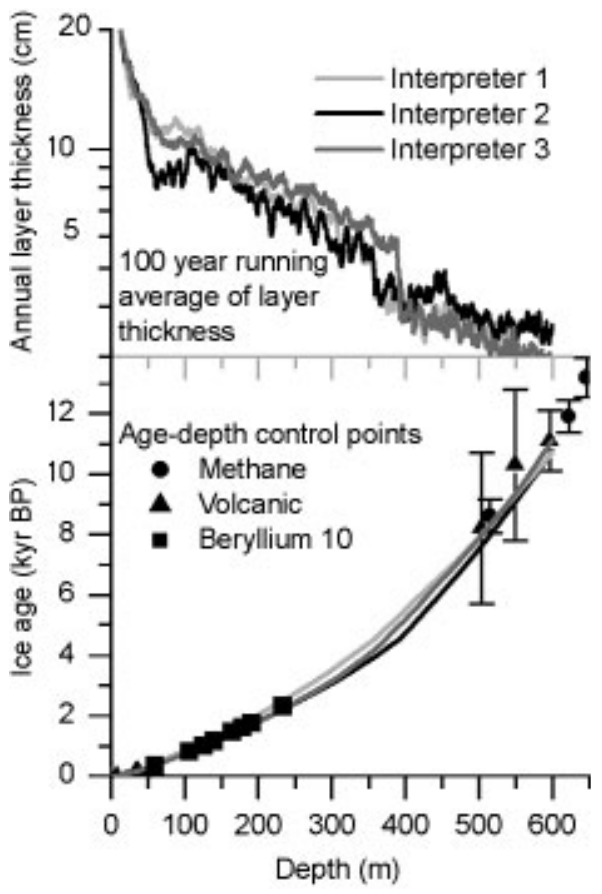

Fig. 3. Comparison of age control points and three manual interpretations of electrical data and visual observations.

a few deeper intervals. The other group interpreted layers to the bottom and extrapolated over intervals of poor ice quality. A comparison of the visual interpretations and the agedepth control points (Tables 1-3) shows the manual interpretations based only on visual observation in Holocene ice are within $5 \%$ of each other and consistently result in ice ages that are slightly younger than the youngest age in the uncertainty intervals of the age-depth control points (Fig. 2). This implies that both visual-stratigraphy groups did not recognize some of the annual layers.

\section{Manual interpretation of multiple records}

The second approach to dating the core used manual interpretation of the electrical and chemical data and incorporated the two visual interpretations. Three individuals reviewed this information, two of whom had participated in the examination and interpretation of the visual stratigraphy. These interpretations (Fig. 3) were done over a 3 year period as the data became available. To select annual layers, the interpreters searched for approximately regularly spaced features in all the records with seasonal variations. This was facilitated by a computer display that showed all the records on one screen with a scale that was optimized for each record and depth. How large and how regularly spaced a feature (such as a peak in the electrical record) had to be before it was indicative of an annual layer was discussed in general terms but was not quantified. The requirements inevitably varied not just between interpreters but also between different interpretation sessions by the same interpreter. In general, there was a preference for features occurring at regular intervals, but exceptions were made for irregularly spaced but abnormally large features. The trade-off between the desire to have prominent peaks at each annual layer vs having annual layers with a regular spacing is the dilemma every interpreter deals with each time a layer is interpreted. It is difficult to discuss the details of manual decisions because they are subjective and the 
Table 4. Size of search windows

\begin{tabular}{cll}
\hline Window & Percentage of average layer & Percentage of average layer \\
No. & thickness below last annual & thickness below last annual \\
& layer to start of search & layer to end of search \\
& window for next layer & window for next layer
\end{tabular}

\begin{tabular}{lrr}
\hline & & \\
1 & 40 & 75 \\
2 & 75 & 125 \\
3 & 125 & 175 \\
4 & 175 & 225 \\
5 & 225 & 250 \\
\end{tabular}

number of decisions made is so large. Interpreters can spend days in seemingly non-productive discussions trying to justify to each other why they decided to lump two features into a single year instead of splitting them into two separate years.

The manual interpretations differ by up to $15 \%$. There are obvious differences in the interpretations of both the age and layer thickness. This was a tedious process that was difficult to carry out in a consistent and repeatable manner. No attempt was made to force the interpretations to match the age-depth control points.

\section{Computer algorithm interpretation}

The third approach to dating the core used a computer algorithm to interpret the data. The first step in the process was to bandpass filter the electrical data so that only features with a wavelength of $1-50 \mathrm{~cm}$ were preserved. This removed short-wavelength measurement features associated with time periods much less than lyear, and long-wavelength features associated with time periods much greater than 1 year. The amplitude of the resulting zero-mean data was normalized by dividing by the standard deviation of a $50 \mathrm{~m}$ long moving window.

The algorithm was designed to mimic the thought process used by the interpreters when they manually interpreted the data. It started by searching for a prominent peak in a depth interval (a window) centered on the depth where the next annual layer was likely to occur. If there was not a peak with sufficient amplitude in this window, then the algorithm searched for a progression of smaller peaks in a progression of different windows. The location and width of the windows depended on the depth of the last annual layer and the average thickness of the preceding 20 annual layers (Table 4).

For a peak to be classified as an annual layer, it had to be a local maximum that rose above the adjacent minimum values on each side of it by more than the specified threshold amplitude. The nominal threshold amplitude was specified as a function of depth. Near the surface the layers are thick, so each measurement spans a relatively short time and the annual layers are well defined. A large nominal threshold amplitude was used to select only the most prominent peaks that indicate the occurrence of shallow annual layers. Deeper down, the layers are thinner due to ice flow, each measurement value spans a longer time interval and the annual layers are not as prominent. A smaller nominal threshold amplitude was used to select both the prominent and less prominent peaks that indicate the occurrence of deeper annual layers. In addition to annual-layer thickness, other factors such as the amount of chemical diffusion, ice
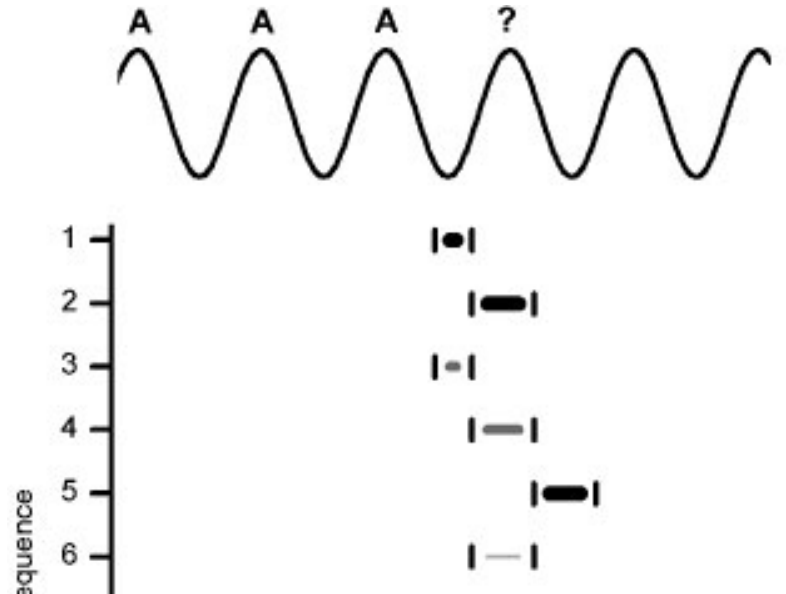

|-1

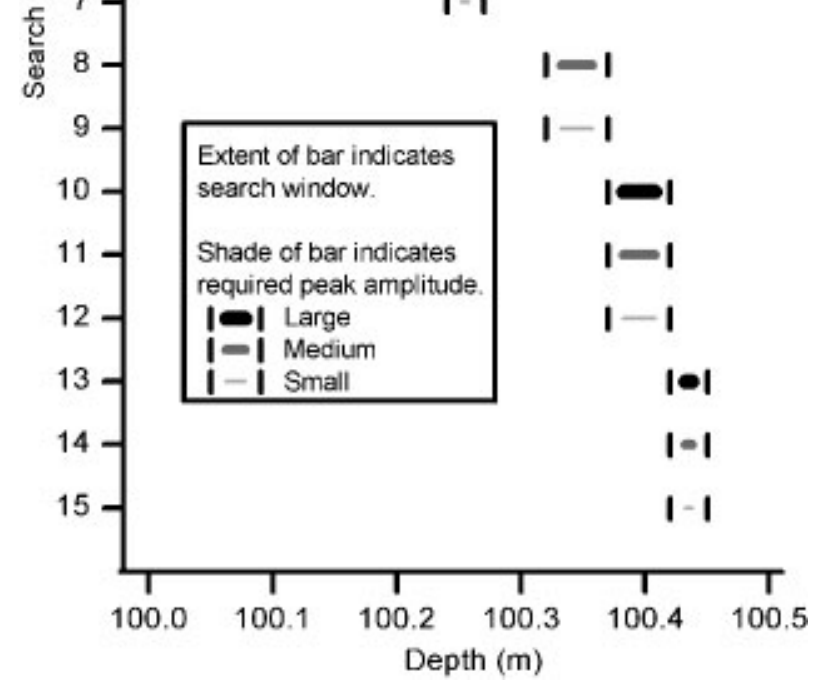

Fig. 4. Illustration of the search sequence. In this example the annual layers are considered to occur at the peaks of a sine wave. Assuming the algorithm has already selected the peaks marked A, the algorithm starts a search for the next annual layer, indicated by '?? To do this, it conducts a sequential set of searches. The search sequence, indicated on the left axis, starts at the top and proceeds downward with subsequent searches until an annual layer is identified. The width of the window that is searched is a function of the thickness of the previous 20 annual layers modulated by the search sequence (Table 4), and for the sine function in this example is indicated by the width of the bars. The amplitude required for a peak to be considered an annual layer is a prescribed function of the depth modulated by a factor (Table 5, right column) that varies as part of the search sequence. The relative amplitude required for a peak to be classified as an annual layer is indicated by the thickness of the bar.

recrystallization and climate conditions may also influence how prominent the annual layers are. The relationship of nominal threshold amplitude to depth was adjusted with a manual, iterative process until the depth-age relationship was consistent with the age-depth control points.

The search sequence for an annual layer (Fig. 4; Table 5) involved searching the windows using various threshold amplitudes (which were a fraction of the specified depthdependent nominal threshold amplitude) until an annual layer was found. The first search is for a large peak associated with a year with less than average ice accumulation. In the first search only prominent years (i.e. large peaks) are selected to avoid misinterpreting minor peaks as years 
Table 5. Search sequence for the annual layers

\begin{tabular}{ccc}
\hline $\begin{array}{c}\text { Search sequence } \\
\text { order }\end{array}$ & $\begin{array}{c}\text { Window } \\
\text { No. }\end{array}$ & $\begin{array}{c}\text { Required amplitude of peak expressed } \\
\text { as per cent of nominal threshold amplitude }\end{array}$ \\
\hline 1 & 1 & 100 \\
2 & 2 & 100 \\
3 & 1 & 70 \\
4 & 2 & 70 \\
5 & 3 & 100 \\
6 & 2 & 40 \\
7 & 1 & 40 \\
8 & 3 & 70 \\
9 & 3 & 40 \\
10 & 4 & 100 \\
11 & 4 & 70 \\
12 & 4 & 40 \\
13 & 5 & 100 \\
14 & 5 & 70 \\
15 & 5 & 40 \\
& &
\end{tabular}

with low ice accumulation. The second search is for prominent years (i.e. large peaks) associated with a year with average accumulation. The sequence starts with a search for a prominent year with less than average ice accumulation because otherwise it would misinterpret two prominent years of low ice accumulation as a single year. For example, consider the case of two years with large peaks but only half the average accumulation. If the sequence started with a search for a large peak at the depth associated with an average amount of accumulation, the two adjoining short years would be interpreted as a single year. Such an approach would bias the interpretation away from lowaccumulation years. To avoid excessively favoring years with low accumulation the sequence searches for prominent years with average accumulation (search 2) before it searches for less prominent years with less than average accumulation (search 3).

Just like a manual interpretation, the search sequence has a large influence on the interpreted distribution of annual-layer thickness. The search sequence is a subjective balance between the importance of interpreting annual layers with a consistent thickness, vs the importance of having a prominent feature associated with each annual layer. The biases of the algorithm interpretation are defined and consistent, which is not the case for a manual interpretation. In this work there was not enough information to justify or evaluate the correctness of any particular bias in the search sequence.

The age-depth relationship for the lower part of the Siple Dome core, where annual layers are not preserved, is being determined by correlating the methane record from the Siple Dome core to the GISP2 core (personal communication from Brook and others, 2003). We chose to make the transition from the time-scale determined by annual layers to the time-scale determined by gas stratigraphy at an age of 8610 years BP This age was selected because it had a good methane stratigraphy tie to GISP2, and below this depth annual layers are difficult to identify. Although we could make an annual-layer-counted time-scale for the Siple Dome core that is independent of GISP2, we chose to force the algorithm interpretation of the Siple Dome annual-layer counting time-scale to have an Ice Age of 8610 years BP at $514.78 \mathrm{~m}$ depth. This results in the global change in atmospheric methane concentration that is recorded in both the

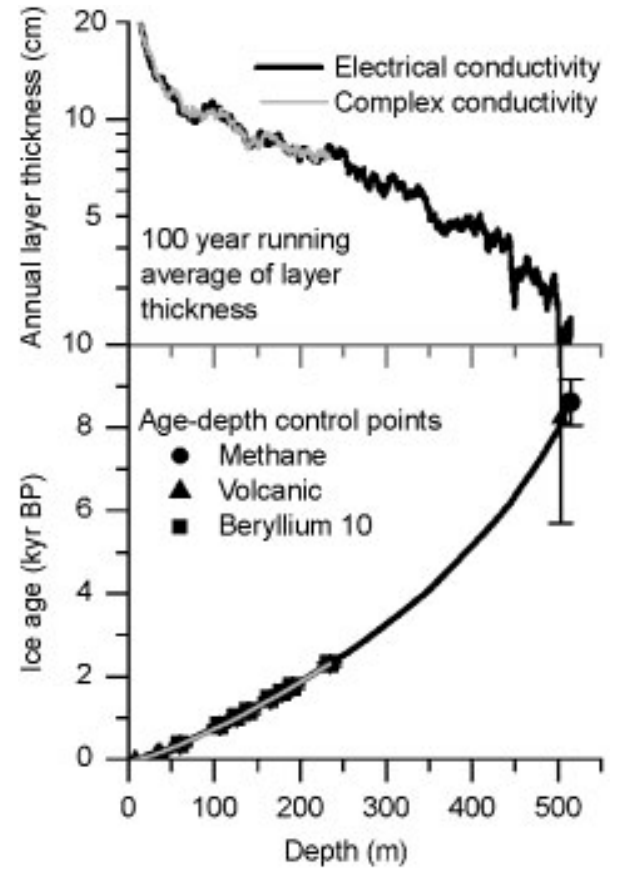

Fig. 5. Comparison of age control points with algorithm interpretation of the electrical data.

Siple Dome and GISP2 cores, to be assigned the same age in both cores. The gas age at this depth is $8330 \mathrm{BP}$ and the methane change is the beginning of the $8200 \mathrm{BP}$ climate event (Alley and others, 1997a). We feel justified forcing the Siple Dome and GISP2 records to agree at this age because the manual multi-parameter and visual-only interpretations of the Siple Dome core, which are not forced to agree with any other records and were independently carried out by several people, are close to the expected uncertainty of 550 years at an age of 8610 years BP and $514.78 \mathrm{~m}$ depth. We do not tie the Siple Dome record to other cores besides GISP2 because doing so would lead to multiple time-scales for the Siple Dome core.

The algorithm interpretations of the complex conductivity and electrical conductivity data (Fig. 5) were forced to pass through the age-depth control points obtained from the volcanic events during the last 200 years, correlation of the ice ${ }^{10} \mathrm{Be}$ and dendrochronology ${ }^{14} \mathrm{C}$ records and the GISP2 methane age-depth control point at 8610 years BP Volcanic events older than 200 years were not used due to the large uncertainty in dating those events. The complex conductivity data could not be used below $250 \mathrm{~m}$ because the spatial resolution of the data was not sufficient to confidently identify the increasingly thinner annual layers below this depth. The interpretations of representative sections of electrical data are shown in Figure 6.

As noted above, the algorithm is designed to mimic the thought process used in manual interpretations and to be consistent in the application of a search sequence. In depth intervals with frequent age--depth control points, the age vs depth relationship is not dependent on the search sequence because the interpretation is forced to agree with the agedepth control points. The thickness of individual layers is strongly controlled by the search sequence. For example, the search sequence could be arranged to favor selection of evenly spaced annual layers without much regard for the amplitude of the associated peaks, or the search sequence could be arranged to favor selection of annual layers associated with large-amplitude peaks without much regard for 

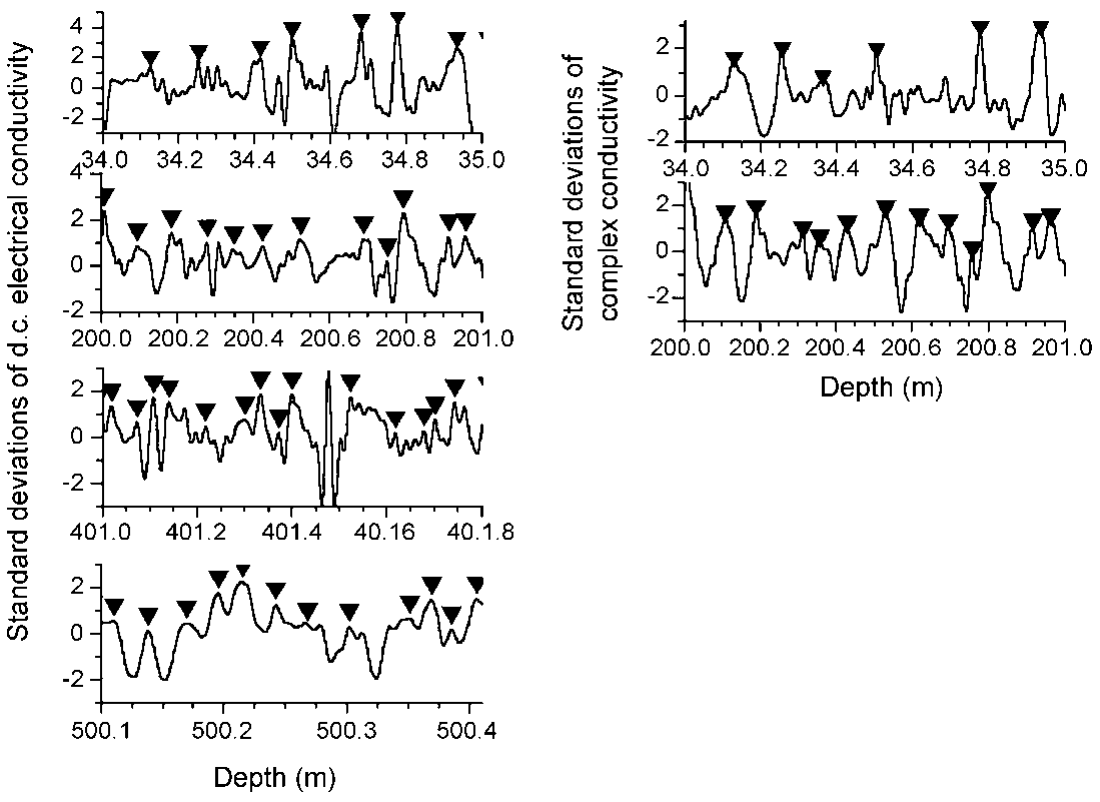

Fig. 6. Examples of annual layers in the electrical data (indicated by triangles) selected by the algorithm. The values have been normalized by dividing by the standard deviation of the data in a sliding $50 \mathrm{~m}$ interval.

the spacing between annual layers. The search sequence used here (Fig. 4; Tables 4 and 5) is a balance between these two approaches. The subjective choice of the search sequence does not influence the layer thickness vs depth profile when the layer thickness profile is averaged over several tens of years because the interpretation is constrained by the age--depth control points. In other situations when there are no age--depth control points, the choice of the search sequence will have a large influence over the interpreted time-scale and the layer thickness vs depth profile. On projects without age-depth control points, multiple search sequences should be employed to evaluate the influence of the search sequence on the time-scale.

In depth intervals where there were no data due to poor core quality, the annual layers were assumed to be as thick as the average of the ten annual layers above and below the interval without any data. There were 13 intervals longer than $1 \mathrm{~m}$ where this interpolation approach was used, four intervals were longer than $1 \mathrm{~m}$ and the longest interval was $2.1 \mathrm{~m}$.

The interpretation algorithm cannot be used on the visual interpretations made by observing the core on a light table because only an interpretation of the location of annual layers is recorded. An instrument is being developed to record the optical characteristics of the core so that on future projects an algorithm can be used to assist in the interpretation of the visual characteristics of the cores. The visual interpretations were extremely helpful in making the manual interpretations and increased our confidence in the algorithm interpretation. Quantitative measurements on the core are required for good dating, but it is still necessary to carefully examine the visible features in each core.

\section{RESULTS}

To assign ages to the Siple Dome core, we have used the visual observations for the top $5 \mathrm{~m}$ where the electrical measurements are difficult to make due to poor consolidation of the firn. From 5 to $250 \mathrm{~m}$, we have used an average of the algorithm interpretations of the complex conductivity and electrical conductivity forced to match the volcanic and ${ }^{10} \mathrm{Be}$ age-depth control points. From 250 to $514 \mathrm{~m}$, we have used the algorithm interpretation of the electrical conductivity data that was forced to be in agreement with the methane stratigraphic tie to the GISP2 core at 8610 years BP We limit the use of the layer counted time-scale to 8610 years BP because of concerns about data quality from previous times.

The ${ }^{10} \mathrm{Be}$ age-depth control points are accurate to approximately $3 \%$, and the methane age-depth control points to approximately $6 \%$. Comparison of the algorithm interpretation of the electrical conductivity and complex conductivity data suggests that the algorithm interpretation is accurate to approximately $3 \%$. We estimate the accuracy of the final interpretation is approximately $5 \%$ in the depth interval $0-230 \mathrm{~m}$ where ${ }^{10} \mathrm{Be}$ data provide a close tie to the ${ }^{14} \mathrm{C}$ dendrochronology record. From 230 to $514 \mathrm{~m}$, there are no age-depth control points, and we estimate the uncertainty may be as high as $10 \%$ in the middle of this depth interval. We are comfortable using the time-scale to determine annual-layer thickness averaged over periods longer than 100 years. This is sufficiently long that occasional problems in the data or interpretation will not significantly influence the result. Our confidence in the annual-layer thickness when averaged over 100 years is justified by the close agreement of the interpretations of the layer thickness obtained from the electrical conductivity and complex conductivity measurements (Fig. 5).

In this work we have used the algorithm interpretation of annual-layer data to interpolate between depths of known age. The uncertainty in the dating is dominated by the uncertainty in the age--depth control points that were used to tune the interpretation. In other situations it may be undesirable, or not possible, to force the time-scale to agree with specified age- ${ }^{-}$epth control points. In these situations the uncertainty of the interpretation will be dominated by the quality of the annual-layer data and implementation of the algorithm. The quality of the annual-layer data is controlled by the characteristics of the drill site (e.g. magnitude of the 
seasonal changes, annual ice accumulation rate, redistribution of surface snow) and by analytical procedures (e.g. what parameters are measured and how those parameters are measured). At depths and locations where the annual layers are regular and well resolved, the optimal characteristics of the algorithm can be identified with confidence and do not greatly influence the interpretation. (For example, it is easy to design an algorithm to select annual layers when they are as regular as a sine wave.) At depths and locations where there are no age--depth control points and annual layers are irregular or not well resolved, the design of the algorithm becomes difficult and subjective.

Without age--depth control points, there is no way to impartially evaluate the design or tuning of an algorithm. It is possible to illustrate the likely range of uncertainty by designing multiple algorithms that select annual layers in agreement with a range of subjective manual interpretations. These algorithms can be tuned to agree with the manual interpretation of short intervals and applied to the entire record to illustrate the cumulative effect of the different approaches to the interpretation. It is not possible to rigorously define an uncertainty for the resulting time-scale because there is no way to rigorously define an uncertainty for the manual interpretations the algorithms were tuned to mimic. Another approach to estimating uncertainty is to use the algorithms on different combinations of data, as was done in this work. This work did not explore the effect of different algorithms on the age--depth scale because the age-depth scale was forced to be consistent with known age- -depth control points and the uncertainty of the timescale is dominated by the uncertainty of those age-depth control points. For situations without age-depth control points it is recommended that multiple-interpretation algorithms be used on multiple datasets to illustrate the range of possible interpretations.

Before the annual-layer thickness calculated from this time-scale can be used to determine ice accumulation rate, local variations in ice flow and accumulation rates associated with changes in the location of the Siple Dome ice divide and surface dunes need to be accounted for. The time-scale is available from the U.S. National Snow and Ice Data Center and is referred to as SDM-A:0-514m:Oct2002.

\section{DISGUSSION}

The manual interpretations are subjective and not consistent with the age--depth control points. There are also inevitable inconsistencies in the manual interpretations. An iterative process could be used to force the manual interpretations to be consistent with the age- $\mathrm{depth}^{-}$control points, but it is not possible to do this in a way that ensures a consistent interpretation of the entire record. The subjectivity in the algorithm interpretation is related to the availability of age-depth control points. The algorithm is well constrained in depth intervals with frequent age--depth control points. The algorithm is as subjective as manual interpretation in depth intervals without age--depth control points. The algorithm provides a consistent approach to the interpretation of the data, and the manual approach inevitably leads to inconsistencies. The algorithm can be easily adjusted to provide a consistent interpretation that matches age-depth control points. As additional age--depth control points are developed in the future, perhaps from additional
${ }^{10} \mathrm{Be}$ analyses or other sources, the algorithm can be rerun to refine the dating, whereas manual interpretations require much greater effort to refine when additional information becomes available.

The algorithm can be used without any control points by defining an amplitude threshold function that identifies annual layers in a way that is acceptable to the subjective opinion of an interpreter. The availability of even a few age-depth control points that do not rely on interpretation of annual layers greatly increases confidence in the timescale and should be a high priority of any ice-core dating effort. Manual interpretation of at least some of the data will always be required to ensure that an algorithm interpretation is reasonable.

\section{ACKNOWLEDGEMENTS}

This work was supported by numerous grants, particularly grant 9526420 from the U.S. National Science Foundation Antarctic Glaciology program, and under the auspices of the U.S. Department of Energy by the University of California, Lawrence Livermore National Laboratory under contract No. W-7405-Eng-48. Special thanks to M. Wumkes for drilling assistance and to the U.S. National Ice Core Laboratory, particularly J. Rhoads, for core handling.

\section{REFERENGES}

Alley, R. B. and G. A. Woods. 1996. Impurity influence on normal grain growth in the GISP2 ice core, Greenland. F. Glaciol., 42(141), 255-260.

Alley, R. B., P. A. Mayewski, T. Sowers, M. Stuiver, K. C. Taylor and P. U. Clark. 1997a. Holocene climatic instability: a prominent, widespread event 8200 yr ago. Geology, 25(6), 483-486.

Alley, R. B. and 11 others. 1997b. Visual-stratigraphic dating of the GISP2 ice core: basis, reproducibility, and application. F. Geophys. Res., 102(C12), 26,367-26,382.

Beer, J. and 6 others. 1988. Information on past solar activity and geomagnetism from ${ }^{10}$ Be in the Camp Century ice core. Nature, 331 (6158), 675-679.

Blunier, T. and E.J. Brook. 2001. Timing of millennial-scale climate change in Antarctica and Greenland during the last glacial period. Science, 291 (5501), 109-112.

De Angelis, M., M. Legrand, J.-R. Petit, N. I. Barkov, Y. S. Korotkevich and V. M. Kotlyakov. 1984. Soluble and insoluble impurities along the $950 \mathrm{~m}$ deep Vostok ice core (Antarctica) - climatic implications. F. Atmos. Chem., 1(3), 215-239.

Devine, J. D., H. Sigurdsson, A. N. Davis and S. Self. 1984. Estimates of sulfur and chlorine yield to the atmosphere from volcanic eruptions and potential climatic effects. 7. Geophys. Res., 89(B7), 6309-6325.

Dunbar, N.W., G. A. Zielinski and D.T. Voisin. 2003. Tephra layers in the Siple and Taylor Dome ice cores, Antarctice: correlations and sources. f. Geophys. Res., 108(B8), 2374. (10.1029/2002JB00208.)

Finkel, R. C. and K. Nishiizumi. 1997. Beryllium 10 concentrations in the Greenland Ice Sheet Project 2 ice core from 3-40 ka. 7. Geophys. Res., 102(C12), 26,699-26,706.

Haberle, S. G. and S. H. Lumley. 1998. Age and origin of tephras recorded in postglacial lake sediments to the west of the southern Andes, 44 degrees S to 47 degrees S. F. Volcanol. Geotherm. Res., 84(3-4), 239-256.

Hamilton, G. S. 2002. Mass balance and accumulation rate across Siple Dome, West Antarctica. Ann. Glaciol., 35, 102-106.

Hammer, C. U. 1983. Initial direct current in the buildup of space charges and the acidity of ice cores. 7. Phys. Chem., 87(21), 4099-4103.

Jeffries, T. E., W. T. Perkins and N. J. G. Pearce. 1995. Measurements of trace elements in basalts and their phenocrysts bt laser probe microanalysis inductively couped plasma mass spectrometry (LPMA-ICP-MS). Chem. Geol. 121(1-4), 131-144.

Kreutz, K. J., P. A. Mayewski, L. D. Meeker, M. S. Twickler, S. I. Whitlow and I. I. Pittalwala. 1997. Bipolar changes in atmospheric circulation during the Little Ice Age. Science, 277(5330), 1294-1296.

Kreutz, K. J., P. A. Mayewski, S. I. Whitlow and M. S. Twickler. 1998. Limited migration of soluble ionic species in a Siple Dome (Antarctica), ice core. Ann. Glaciol., 27, 371-377. 
Meese, D. A. and 8 others. 1997. The Greenland Ice Sheet Project 2 depth-age scale: methods and results. 7. Geophys. Res., 102(C12), 26,411-26,423.

Moore, J. C., E.W. Wolff, H. B. Clausen and C. U. Hammer. 1992. The chemical basis for the electrical stratigraphy of ice. 7. Geophys. Res. 97(B2), 1887-1896.

Palais, J. M., S. Germani and G. A. Zielinski. 1992. Inter-hemispheric transport of volcanic ash from a 1259 A.D. volcanic eruption to the Greenland and Antarctic ice sheets. Geophys. Res. Lett., 19(8), 801-804.

Siegenthaler, M. J. and J. Beer. 1988. Model comparison ${ }^{14} \mathrm{C}$ and ${ }^{10} \mathrm{Be}$ isotope records. In Stephenson, F. R. and A.W. Wolfendale, eds. Secular solar and geomagnetic variations in the last 10,000 years. Dordrecht, Kluwer Academic Publishers, 315-328.
Stuiver, M. and 9 others. 1998. INTERCAL98 radiocarbon age calibration, 24,000-0 cal BP. Radiocarbon, 40 (3), 1041-1083.

Taylor, K. and 6 others. 1992. Ice-core dating and chemistry by direct-current electrical conductivity. F. Glaciol., 38(130), 325-332.

Wilch, T. I., W. C. McIntosh and N.W. Dunbar. 1999. Late quaternary volcanic activity in Marie Byrd Land: potential ${ }^{40} \mathrm{Ar} /{ }^{39} \mathrm{Ar}$ dated time horizons in West Antarctic ice and marine cores. Geol. Soc. Am. Bull., 111(10), 1563-1580.

Zielinski, G. A. and 7 others. 1997. Volcanic aerosol records and tephrochronology of the Summit, Greenland, ice cores. 7. Geophys. Res., $102(\mathrm{Cl} 2), 26,625-26,640$.

MS received 25 August 2003 and accepted in revised form 15 February 2004 